\title{
Design of hybrid beam-to-column joints between RHS tubular columns and I-section beams
}

\author{
L. Simões da Silva \\ ISISE, Civil Engineering Department, University of Coimbra, Coimbra, Portugal \\ Y. Harada \\ Department of Architecture, Faculty of Engineering, Chiba University, Chiba, Japan
}

\begin{abstract}
This paper presents the proposal of a framework and operational proposal for the inclusion of hybrid joints between tubular columns and open section beams in EC3$1-8$, providing a design specification for the most common types of joint typologies and allowing for the evaluation of their stiffness and resistance. The code conform specification further characterizes the equivalent cross-section component model for the tube zone that contributes to the joint behaviour, including the out-of-plane deformation of the column faces.
\end{abstract}

\section{INTRODUCTION}

Tubular steel columns provide efficient structural solutions because they combine several advantages when compared to open cross-section alternatives:

- Appealing aesthetics

The use of tubes usually leads to pleasant visual results, being the undisputed option whenever the structure is exposed as it is the case of stadia, airports, large halls and sports arenas.

- Balanced mechanical performance

Structures with tubular profiles present a very high strength-to-weight ratio because the various failure modes are well balanced with respect to tension, major and minor axis bending, compression and torsion, minimizing the needs for bracing and also providing easy ways of obtaining increased resistance by composite action with e.g. concrete filling.

- Better fire performance

Structures with tubular profiles present a better fire performance because of the reduced exposed area.

- Easier fabrication and erection

The production process of tubes leads to smooth surfaces and no sharp corners, therefore improving corrosion resistance. Additionally, because of the balanced resistance of the tubes, erection is simpler, with less temporary bracing and supports.

- More economic life-cycle costs

Tubular structures present life-cycle cost savings due to smaller fire protection and painting costs (smaller surface area), facilitating maintenance operations and leading to a longer service life.

Additionally, on a more global note, steel structures are more environmentally friendly because steel is infinitely recyclable without loss of characteristics and steel solutions are easily reusable (Simões da Silva et al, 2021a). Furthermore, recent advances in steel production with 
coal-free Hydrogen-based reduction - HYBRIT (LKAB, 2021) will further reduce the carbon footprint of steel production.

However, concerning connections, tubular profiles present the disadvantage of not allowing easy access to the inside of the tube. This leads to difficulties in using traditional bolted solutions. These difficulties are further amplified by the usual small thickness of the tubes that leads to the possibility of additional critical and complex failure modes.

Hybrid bolted beam-to-column joints connecting tubular columns to open I-section beams are still nowadays not specified in Eurocode 3, part 1-8 (2005) or the revised version that is currently in its final stages of approval (2021), henceforth denoted prEC3-1-8, despite their widespread use. Invariably, such joints are semi-rigid and partial strength and highly susceptible to the deformability of the column faces, which is still the missing component in the prEC3-1-8 specification. It is the objective of this paper to present efficient solutions for the connection of tubular columns to open I-section profiles, to discuss the specific aspects of the behavior of these joints and to provide a design proposal in code format that complies with the EC3-1-8 methodology for the design of joints.

\section{CONNECTION SYSTEMS FOR HOLLOW SECTION TUBES}

\subsection{Conceptualization}

There are four groups of solution strategies to connect open sections to tubes given the difficulties described above:

- Welded joints: welded beam-to-column joints require in-situ welding; hence, they are not interesting solutions, both from an economic point of view as well as from safety and technical criteria and will not be further addressed in this paper.

- Bolted joints using special fasteners: solutions whereby the beam is directly attached to the column face using end plates and special fasteners that can be installed and tightened from the outside.

- Bolted joints whereby the beam is bolted to plates or channels welded to the column face: these solutions allow the use of standard bolts with access to tighten them from both sides.

- "Through-diaphragm" joints: joints whereby continuity plates (diaphragms) are inserted into the column tube; however, although providing rigid connections, these joints are very expensive to manufacture.

\subsection{Special fasteners}

In order to overcome the difficulty of accessing the inside of a tube, several types of solutions were developed, including special fasteners in order to allow positioning and tightening only from one side. The following three types of solutions are described in the following paragraphs:

- Welded studs (Figure 1): this type of solution presents the drawback that the bolts may be damaged during transport and erection; furthermore, it is very difficult to position the beams and to achieve continuous contact between the endplate and the column face because of the welds around the bolts. The performance of this type of solution is reasonable assuming that welding is performed adequately.

- Threaded holes (Figure 2): This type of solution consists of the execution of threaded holes that can be used with standard bolts (e.g. Flowdrill system). The system is adequate for thicknesses varying from $5 \mathrm{~mm}$ to $12.5 \mathrm{~mm}$ and bolts M-16 to M-20 but the main disadvantage of the system relates to the fact that it does not allow for tolerances.

- Special fasteners (Figure 3): they allow the use of standard holes with normal or oversize tolerances and they rely on the expansion of the blind end of the bolt that is mechanically connected to the parts that will be joined. These systems are normally proprietary systems from various manufacturers such as Huck International Inc, Lindapter International, 


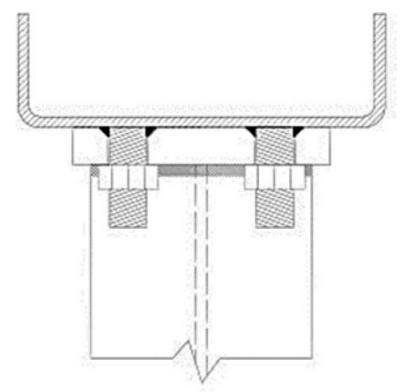

Figure 1. Welded studs.

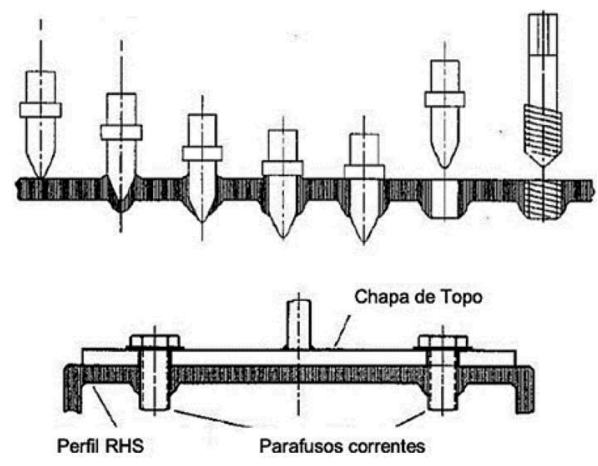

Figure 2. Threaded holes: Flowdrill system.

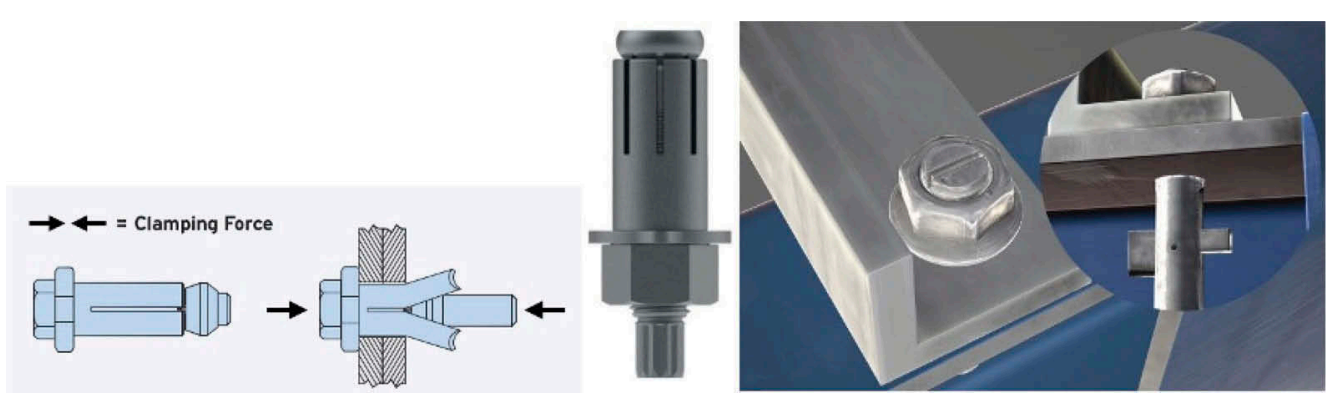

Figure 3. Special fasteners.

AJAX Pty, BlindBolt Ltd and TCB Ltd. The various systems have been extensively studied by several authors (Yeomans, 1998; France et al, 1999; Tizani and Ridley-Ellis, 2003; Tizani et al, 2013; Oktavianus, 2018).

\subsection{Joint typologies}

Depending on the desired performance of the joint, several joint typologies are usually adopted to connect tubular columns to open section beams. Whenever only shear force transfer is desired, a fin plate connection, illustrated in Figure 4, is the usually preferred solution because of its ease of fabrication, easy erection due to the straightforward positioning of the beam and good tolerances. 
From a design point of view, some degree of fixity at the beam ends has a very favorable impact on the design of the beam and the control of deflections. In this case, solutions that provide partial moment resistance are preferred. The first group consists of full or partial depth end-plate joints directly attached to the column face using special fasteners (Figure 5a), while the second group corresponds to bolted reverse channel joints (Figure 5b).

Finally, if rigid joints that satisfy the overstrength criteria are required, then complex and expensive through-diaphragm joints are necessary.

\section{BEHAVIOUR OF THE RHS CONNECTION ZONE}

\subsection{Introduction}

The behavior of the joint typologies listed in sub-section 2.3 may be established by combining the behavior of two distinct zones, illustrated in Figure 6: (i) ZONE A: the section of the tube that is mobilized by the connection; and (ii) ZONE B: the connection zone.

The behavior of the connection zone is independent from the type of column cross-section: it follows the specifications of clause 8 of prEC3-1-8 (2021). The exception relates to the reverse channel joint, whereby the above statement is only applicable for the sub-zone B.2, because the components that are active in zone B.1 are currently not specified in prEC3-1-8. This specific case will be addressed later in this paper.

The behavior of the tube zone is complex because of the couplings between the column faces. To simplify the problem, firstly, it is necessary to understand the nonlinear out-of-plane behavior of the isolated column face (Harada and da Silva, 2019a). Secondly, the interactive

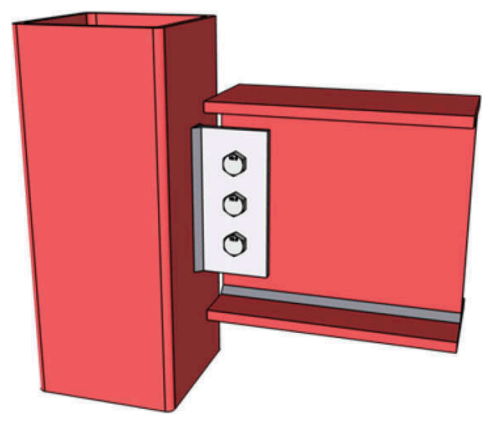

Figure 4. Fin plate joint.

a)

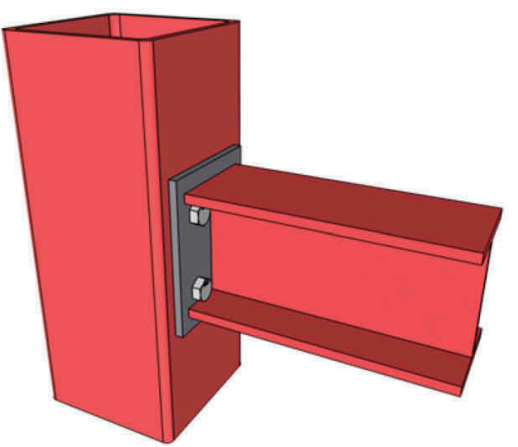

b)

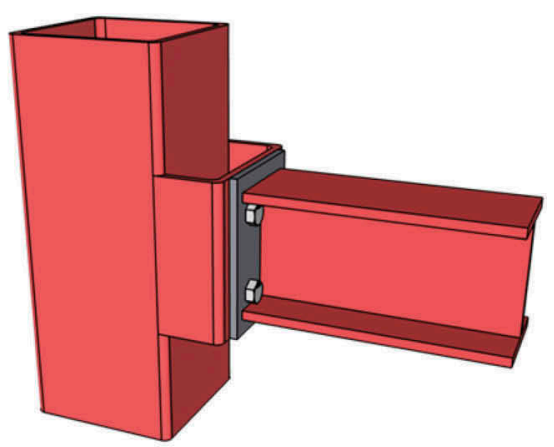

Figure 5. Partial strength semi-rigid bolted joints. a) end-plate joints with blind bolts b) reverse channel joints. 


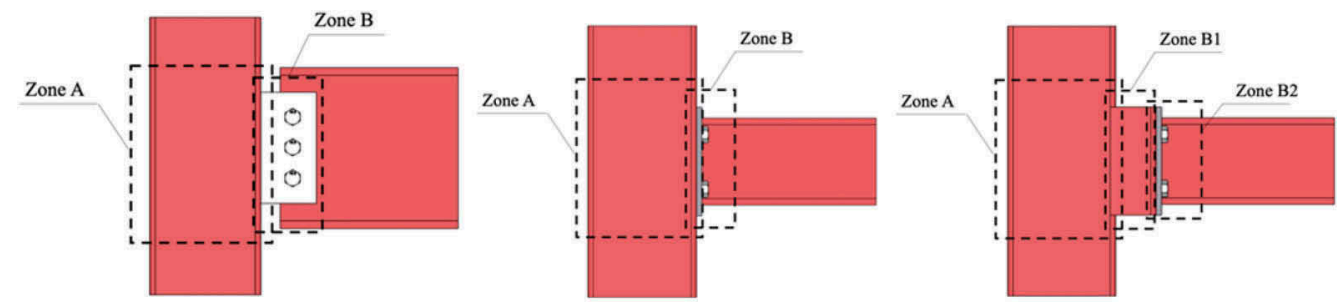

Figure 6. Definition of the zones of each joint typology.

behavior of the multiple column faces is treated in the form of a novel joint component, the "equivalent cross-section" component model (Harada and da Silva, 2019b). Both aspects are addressed in detail in the next sub-sections.

\subsection{Out-of-plane behavior of an isolated column face}

The out-of-plane behavior of a loaded isolated column face depends on various factors:

- Shape and orientation of the connecting element (annular, corresponding to a bolt head, rectangular or built-up shape, longitudinal or transverse with respect to the column axis).

- Type of action transferred by the connecting element (inwards or outwards force, bending moment or shear force), evaluated at the mid-plane of the column face.

- Position of the connecting element with respect to the column face centerline (centric or eccentric).

The multiple failure modes associated to yielding of the column face may be a consequence of a pure bending mechanism, a punching shear mechanism or a mixed mechanism, involving both shear and bending. For high width-to-thickness ratios of the column face, the membrane forces will decisively contribute to the ultimate resistance and second-order effects play a major role. The deformability of the column face is also significant and needs to be assessed to establish the stiffness of the joint.

\subsubsection{Plastic resistance}

Several authors have addressed the evaluation of the plastic resistance of a column face loaded out-of-plane. Yield-line theory is invariably used to derive design expressions. For longitudinal rectangular plates welded to the column face, Kosteski et al (2003) have proposed a design expression that is adopted in EC3-1-8. This equation was recently adopted (Simões da Silva et al, 2021) for a reverse channel welded to the column face, symmetrically placed with respect to the centerline of the column. For transverse rectangular plates welded to the column face or bolts attached to the column face through an endplate, several models are available: Wardenier et al (2007) that is adopted in EC3-1-8, the improved and more accurate proposal by Gomes et al (1996), the simplified expressions by Yeomans (1998) and SCI (2005) that is adjusted to deal with special fasteners such as Hollobolts and the recent proposal by Wang and Wang (2016) that was experimentally calibrated to a set of 14 test results.

\subsubsection{Stiffness}

Concerning stiffness, for end-plate joints directly attached to the column face, Simões da Silva et al (2003) have proposed an equivalent strip model that allows the calculation of the initial stiffness and the membrane stiffness of the column face. This model was recently extended to cyclic out-of-plane behavior by Harada and Simões da Silva (2019a). For single or double longitudinal rectangular plates welded to the column face, Simões da Silva et al (2021b) proposed design expressions for this component that allow the calculation of the initial stiffness of fin plate or reverse channel configurations. 


\subsection{Equivalent cross-section tube model}

The "equivalent cross-section" component model allows to consider the local deformation of the cross-section of the RHS column tube. In relation to this approach, the "ring" model is well established in the field of tubular structures: to estimate the local behavior of a circular tube (CHS), its cross-section is modeled as a planar framework with the cross-section's shape (Togo, 1967). For RHS tubes, the deformable tubular column section can be modeled as a planar framework with four equal beam members with the same length $L$, which corresponds to the plate width of the column plate, and the flexural rigidity EI. This cross-section component is supported by four pin supports at their four corners, as shown in Figure 7.

According to Harada \& Simões da Silva (2019b), the relation between the force and the deformation vectors (eq. (6)), which have four elements corresponding to the four column plates in the cross-section component is the stiffness equation of the cross-section component. Eq. (6) can be regarded as a description of the interaction between the behaviors of the four column plates. The flexural rigidity is determined so that the deflection of the side beam coincides with the out-of-plane deformation of the column plate, obtained as described in subsection 3.2.2. The nonlinear behavior of the single column plate is assumed to be decomposed into two contributions, i.e., elastic-plastic and membrane contributions: the elastic-plastic contribution is modeled by plastic hinges on the side beams, and the membrane contribution by uniaxial membrane springs at the middle of the side beams. This modeling approach assumes that the elastic-plastic behaviors of the four column plates can interact while the membrane behaviors of the four plates are independent.

\section{COMPONENT MODEL}

The design of the 3 joint typologies between I-section beams and RHS tubular columns is based on the component method. It requires the calculation of the applied internal forces acting on the joint and the identification of the active components. Following prEC3-1-8, the safety of each joint is established, as appropriate, by satisfying equations (1) to (3):

$$
\begin{gathered}
N_{i, E d} \leq N_{i, R d} \\
V_{i, E d} \leq V_{i, R d} \\
M_{i p, i, E d} \leq M_{i p, i, R d} M_{o p, i, E d} \leq M_{o p, i, R d}
\end{gathered}
$$

where $N_{i, E d}$ is the applied axial force, $V_{i, E d}$ is the applied shear force, $M_{i p, i, E d}$ is the applied bending moment in the plane of the joint, $M_{o p, i, E d}$ is the applied out-of-plane bending moment, $N_{i, R d}$ is the axial force resistance, $V_{i, R d}$ is the shear force resistance, $M_{i p, i, R d}$ is the bending moment resistance in the plane of the joint and $M_{o p, i, R d}$ is the out-of-plane bending moment resistance.
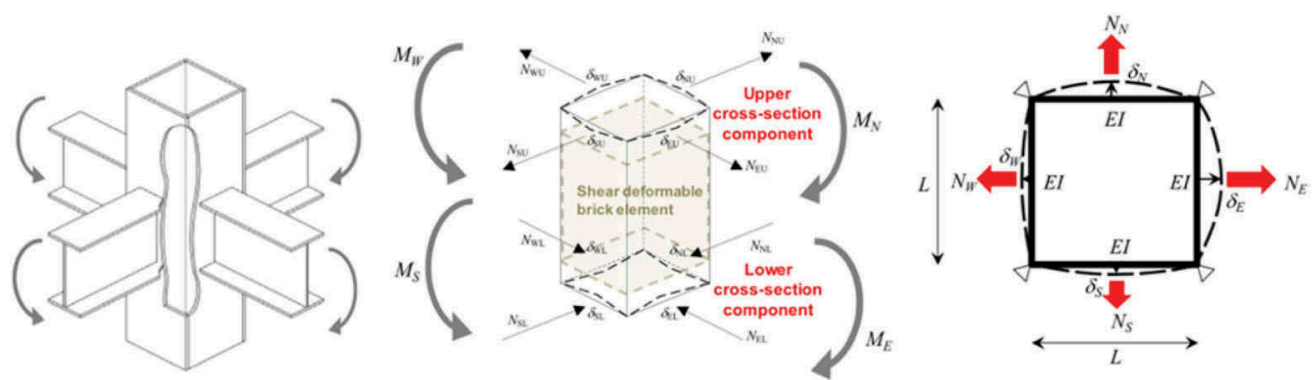

Figure 7. Outline of the equivalent cross-section component model (reproduced from Harada \& Simões da Silva, 2019b). 

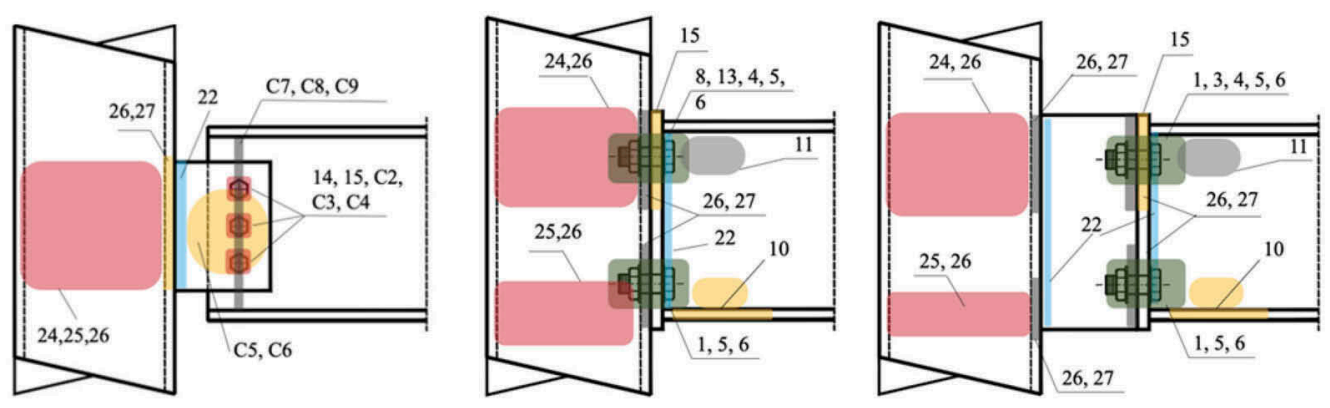

Figure 8. Active components.

Figure 8 identifies the active components for each of the 3 joint typologies. The fin plate joint follows most of Annex C of prEC3-1-8 (Jones and Wang, 2011) except for Zone A, related to the local deformation of the cross-section of the RHS tube. For the endplate joints, Zone B also follows the specifications in Annex B of prEC3-1-8, but it must be combined with the equivalent cross-section component model to tackle the behavior of the tube zone. Several subtypes exist that have been widely studied, namely the connection to concrete filled tubes (Wang et al, 2009; Wang \& Zhang, 2017; Li et al, 2019; Fan et al, 2021) or solutions with through-thickness long bolts (Van Long et al, 2015; Zhou et al, 2019). Finally, the reverse channel joint (Lopes et al, 2013) combines the standard behavior of end-plate joints (Zone B.2) with the equivalent cross-section component model (Zone A) and the specific behavior of the reverse channel (Zone B.1) that shares several features with the column face (Heistemann et al, 2015; Lopes et al, 2015).

\section{CODE SPECIFICATION}

\subsection{Framework and proposed implementation}

prEC3-1-8 follows a component methodology for the evaluation of the structural properties (resistance, stiffness and deformation capacity) of the various joint typologies. Clause 9, Hollow section joints, constitutes the exception, although a Technical Specification (CEN, 2021) is currently being prepared based on Weynand et al (2015) that specifies the design of hollow section joints in a component method format.

Clause 8 of prEC3-1-8 deals with joints between open section members while clause 9 deals with hollow section joints, following Wardenier et al (2010). Hence, a new clause 10 is proposed that addresses hybrid joints, meaning joints between hollow sections and open sections. Also, according to the new structure of prEC3-1-8, the new components that are currently not specified in prEC3-1-8 are added to Annex A and a new annex corresponding to the specific joint typologies addressed in this paper is specified: Annex E - I or H-section beam-to-tubular column joint configurations.

The following sub-sections briefly summarize the proposed implementation, in code format.

\subsection{Clause 10}

\subsubsection{1 - General}

(1) The design methods in Clause 10 should be used to determine the structural properties of joints connecting hollow section members and open cross-section members in framed structures. To apply these methods, joints should be modelled as an assembly of basic components. 
(2) The basic components identified in Table 10.1 (Table 1) should be used. Their properties should be determined in accordance with the provisions given in Annex A. Other basic components may be used provided their properties are based on tests, or analytical and numerical methods supported by tests, see Annex D of EN 1990 (2003).

(3) The design methods for basic joint components given in this Standard are of general application and may also be applied to similar components in other type of joint configurations. However, the specific design methods for determining the design moment resistance, rotational stiffness and rotation capacity of a joint are based on an assumed distribution of internal forces for the joint configurations indicated in Annex E. For other joint configurations, design methods for determining these properties should be based on appropriate assumptions for the distribution of internal forces.

\subsubsection{2 - Structural properties}

(1) The structural properties of joints should be based on the properties of its relevant components, which should be chosen among those in Table 10.1 (Table 1).

(2) The relationships between the properties of the basic components of a joint obtained from Annex A and the structural properties of the joint should be in accordance with Annex E for I or H-section beam-to-tubular column joint configurations.

\subsubsection{3 - Equivalent cross-section component model for RHS tubular members}

\subsection{1 - Application}

(1) The equivalent cross section component model, see Figure 10.1 (Figure 9), may be used to model the design resistance and the stiffness of the following basic components in joints connecting beams or trusses to a tubular RHS or SHS columns:

- RHS column face in out-of-plane bending.

- RHS column face in punching shear.

(2) The equivalent cross-section component model is applicable to the joint typologies illustrated in Figures 3 to 5.

\subsection{2 - Modes of failure}

(1) The possible modes of failure of the faces of the equivalent cross-section component model may be assumed to be similar to those expected to occur in the basic component that it represents.

\subsection{3 - Total effective length}

(1) The total effective length $\Sigma l_{\text {eff }}$ of each face of the equivalent cross-section component model should be such that the design resistance of each face is equivalent to that of the basic joint component that it represents.

NOTE The effective length of the equivalent cross section is a notional length and does not necessarily correspond to the physical length of the basic joint component that it represents.

10.3.4 - Design out-of-plane bending resistance

(1) The design out-of-plane bending resistance of a face should be determined from:

Table 1. Table 10.1 - Basic joint components.

\begin{tabular}{lll}
\hline Component name & Designation & Ref. to appl. rules \\
\hline RHS side wall in tension & $\mathrm{t}, \mathrm{tcsw}$ & A.24 \\
RHS side wall in compression & $\mathrm{c}, \mathrm{tcsw}$ & A.25 \\
RHS face in out-of-plane bending & $\mathrm{f}, \mathrm{tcf}$ & A.26 \\
RHS face in punching shear & ps,tcf & A.27 \\
RHS side wall in shear & tcsw & A.28 \\
RHS side wall in punching shear & tcps & A.29 \\
\hline
\end{tabular}



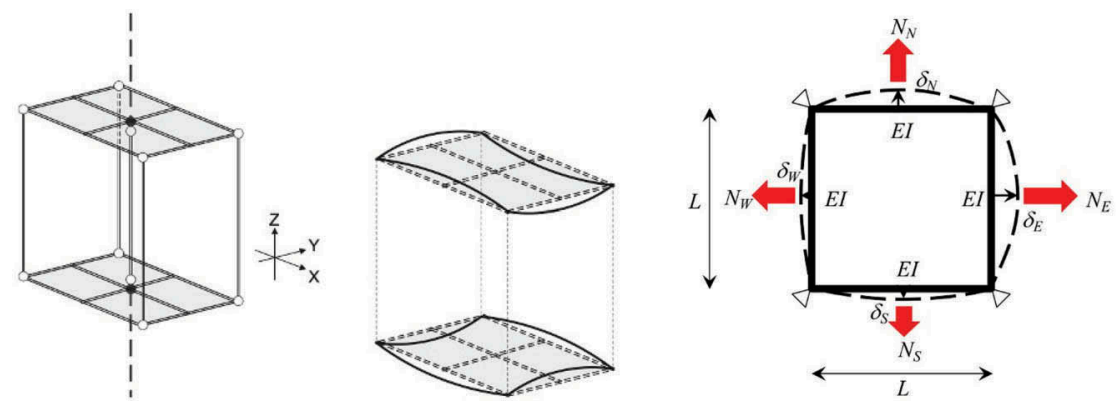

Figure 9. Figure 10.1 - Equivalent cross-section component model.
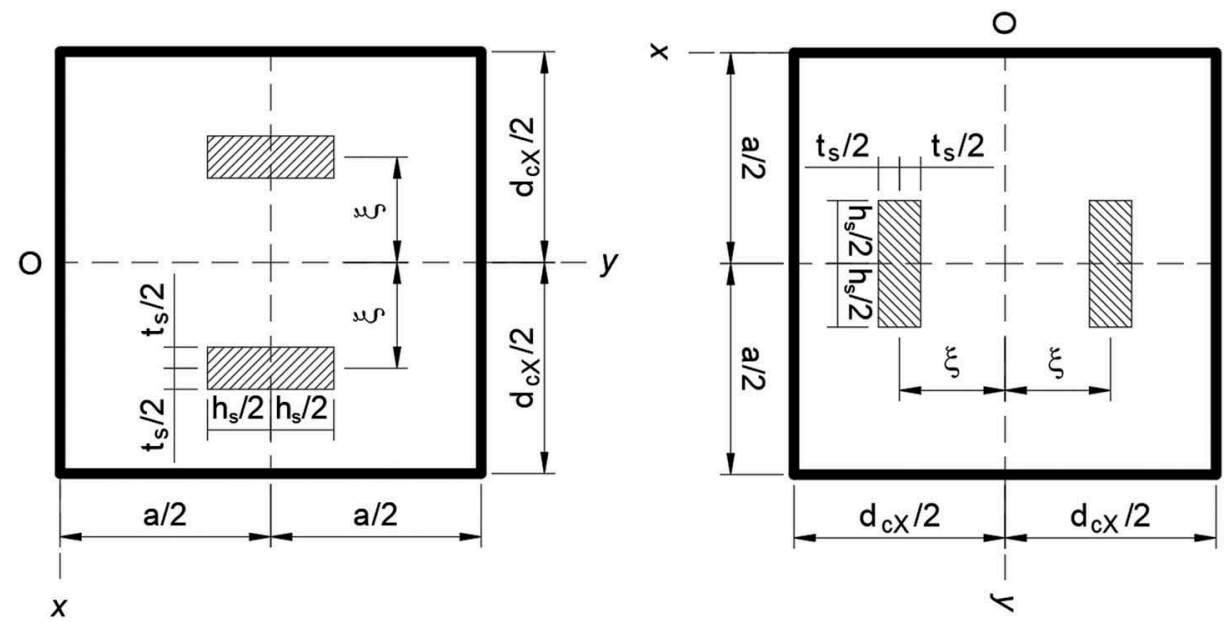

Figure 10. Figure A.16 - Types of loading on the face of the tube (reproduced from Simões da Silva et al, 2021b).

$$
F_{t, t c f, R d}=Q m_{p l} \sum l_{\text {eff }}
$$

where $Q$ is a factor and $\Sigma l_{\text {eff }}$ is the total effective length, both given in Annex A, with

$$
m_{\mathrm{pl}}=\frac{t^{2} f_{y}}{4 \gamma_{M 0}}
$$

where $t$ is the thickness, $f_{y}$ is the yield stress and $\gamma_{M 0}$ is the partial factor.

\subsection{5 - Design out-of-plane bending stiffness}

(1) The 3D interaction between the flexibility of the column faces of RHS tubular members must be accounted for in the determination of its initial stiffness.

(2) The 3D interaction between the flexibility of the column faces of different plug-and-play connections may be accounted for using the equivalent cross-section component model defined in Figure 10.1 with 


$$
\left[\begin{array}{l}
P_{1} \\
P_{3} \\
P_{2} \\
P_{4}
\end{array}\right]=[K]\left[\begin{array}{c}
\delta_{1} \\
\delta_{3} \\
\delta_{2} \\
\delta_{4}
\end{array}\right]=\left[\begin{array}{llll}
k_{b 1} & k_{b 3} & k_{h 2} & k_{h 2} \\
k_{b 3} & k_{b 1} & k_{h 2} & k_{h 2} \\
k_{b 2} & k_{b 2} & k_{h 1} & k_{h 3} \\
k_{b 2} & k_{b 2} & k_{h 3} & k_{h 1}
\end{array}\right]\left[\begin{array}{c}
\delta_{1} \\
\delta_{3} \\
\delta_{2} \\
\delta_{4}
\end{array}\right]
$$

where $k_{b i}, k_{h i}$ are the initial stiffness coefficients to be determined according to A.26, $P_{i}$ is the load at cross section face $\mathrm{i}$ and $\delta_{i}$ is the deformation of the section face $i$.

\subsection{Structural properties of basic components}

\subsubsection{A.26-RHS face in out-of-plane bending}

\section{A.26.1 - Field of application}

(1) This clause applies to the two cases defined in Figure A.16 (Figure 10): the face may be loaded by:

- Face loaded by two transverse strips: two transverse rectangular loaded areas, approximately corresponding the flanges of an open section or a row of bolts of an end plate

- Face loaded by two longitudinal symmetrical strips: two vertical rectangular loaded areas, corresponding to a socket or a reverse channel welded to the column face.

(2) For both cases, a single plate is a valid limiting case, corresponding to a vertical or a horizontal fin plate.

(3) The two strips may be loaded with same sign forces (both tension or both compression), corresponding to a tensile or compressive joint or forces with a different sign (one tension and the other compression), corresponding to a bending moment.

\section{A.26.2 - Design resistance}

(1) The design resistance of a RHS wall face in out-of-plane bending is given by an appropriate yield line model and should be determined as follows:

$$
F_{t, c b}=\min _{i} F_{t, c b, i}=\min _{i} \frac{Q_{u, i} Q_{f} f_{y 0} t_{0}^{2}}{\gamma_{M 0}}
$$

with:

- $Q_{f}$ chord stress factor.

- $Q_{u, i}$ mechanism factor, that depends on the appropriate yield line model and the following geometrical parameters:

$-\beta$ ratio of the plate width $b_{s}$ to the column width $b_{0}$;

- $\eta$ ratio of the plate depth $h_{s}$ to the column width $b_{0}$.

\section{A.26.3 - Stiffness coefficient}

(1) The stiffness coefficients, $k_{b i}, k_{h i}$, of the face in out-of-plane bending are obtained from Harada \& Simões da Silva $(2019 \mathrm{a}, \mathrm{b})$ for a face loaded by two transverse strips or Simões da Silva et al (2021b) for a face loaded by two longitudinal symmetrical strips.

\subsubsection{A.27 - RHS face in punching shear}

\section{A.27.1 - Field of application}

(1) This clause applies to the two cases defined in Figure A.16 (Figure 10): the face may be loaded by:

- Face loaded by two transverse strips: two transverse rectangular loaded areas, approximately corresponding the flanges of an open section or a row of bolts of an end plate

- Face loaded by two longitudinal symmetrical strips: two vertical rectangular loaded areas, corresponding to a socket or a reverse channel welded to the column face. 


\section{A.27.2 - Design resistance}

(1) The design resistance of a RHS wall face in punching shear is given by an appropriate yield line model and should be determined as follows:

$$
F_{t, c p s}=\frac{f_{y 0}}{\sqrt{3} \gamma_{M 0}} t_{0} l_{p, e f f}
$$

where $l_{p, e f f}$ is the effective length of the face in punching shear that depends on the appropriate yield line model.

A.27.2 - Stiffness coefficient

(1) The stiffness coefficient of the face in punching shear is taken as infinity.

$$
k_{p s, t c f}=\infty
$$

\subsection{Annex E-I or H-section beam-to-tubular column joint configurations}

5.4.1 E.1 - Scope

(1) This Annex applies to bolted joints between RHS tubular columns and I-section beams according to Figures 3 to 5.

5.4.2 E.2 - Design resistance

(1) Joints should be designed to resist the bending moments, axial forces, and shear forces applied to the joints by the connected members.

(2) The stresses due to internal forces and moments in a member may be assumed not to affect the design resistances of the basic components of a joint.

\subsubsection{E.3 - Rotational stiffness}

(1) The rotational stiffness of a joint should be determined from the flexibilities of its basic components, each represented by an elastic stiffness coefficient $k_{i}$ obtained from Annex A.

(2) For bolted end plate joints with more than one row of bolts in tension, the stiffness coefficients $k_{i}$ for the related basic components should be combined.

\section{CONCLUDING REMARKS}

This paper presented the proposal of a framework and operational proposal for the inclusion of hybrid joints between tubular columns and open section beams in EC3-1-8, providing a design specification for the most common types of joint typologies and allowing for the evaluation of their stiffness and resistance. The equivalent cross-section component model for the tube zone is able to capture the 3D interactions between the column faces of RHS tubes and thus allow to efficiently assess the contribution of the column faces towards the momentrotation response of these joints.

\section{REFERENCES}

LKAB. 2021. HYBRIT - Towards Fossil-Free Steel. https://www.lkab.com/en/about-lkab/technologicaland-process-development/research-collaborations/hybrit-for-fossil-free-steel/accessed 2021/03/13.

CEN. 2005. EN 1993-1-8: Eurocode 3 - Design of steel structures - Part 1-8: Design of joints. 2005 (+AC:2005 +AC:2009)

CEN. 2021. prEN1993-1-8: Eurocode 3 - Design of steel structures - Part 1-8: Design of joints (March 2021). 
CEN. 2003. EN 1990: Eurocode - Basis of structural design. 2003

CEN. 2021. TS 1993-1-801: Hollow section joint design according to the component method. First draft.

Fan, J., Zhao, J. \& Gao, W. 2021. Moment-rotation model of endplate blind bolted joints with CFST column. Journal of Constructional Steel Research 176: 106446.

France, J.E., Davison, J.B. \& Kirby, P.A. 1999. Strength and Rotational Response of Moment Connections to Tubular Columns using Flowdrill Connectors. Journal of Constructional Steel Research 50: 1-14.

Gomes, F.T., Jaspart, J-P. \& Maquoi, R. 1996. Moment capacity of beam-to-column minor axis joints. In: Proceedings of IABSE international colloquium on semi-rigid structural connections, Istambul, Turkey. IABSE: 319-326.

Harada, Y. \& Simões da Silva, L. 2019. Three-dimensional macro-modelling of rectangular steel hollow section beam-to-column joints under cyclic loading - Part 1: Cyclic out-of-plane behaviour of single isolated column plate, Journal of Constructional Steel Research 162: 105713.

Harada, Y. and Simões da Silva, L. 2019. Three-dimensional macro-modelling of rectangular steel hollow section beam-to-column joints under cyclic loading - Part 2: Modelling by an extended component-based approach. Journal of Constructional Steel Research 162: 105714.

Heistermann, C., Koltsakis, E., Veljkovic, M., Lopes, F., Santiago, A. \& Simões da Silva, L. 2015. Initial stiffness evaluation of reverse channel connections in tension and compression. Journal of Constructional Steel Research, 114: 119-128.

Jones, M.H. \& Wang, Y.C. 2011. Shear and bending behaviour of fin plate connection to concrete filled rectangular steel tubular column - Development of a simplified calculation method. Journal of Constructional Steel Research 67: 348-352.

Li, B., Wang, J., Lu, Y., Zhang, Z. \& Wang, J. 2019. Seismic response tests and analytical assessment of blind bolted assembly T CFST frames with beam-connected SPSWs. Engineering Structures 178: 343-360.

Lopes, F.C., Santiago, A., Simões da Silva, L., Heistermann, T., Veljkovic, M. \& da Silva, J.G. 2013. Experimental behaviour of the reverse channel joint component at elevated temperatures. International Journal of Steel Structures, 13(3): 1-14.

Lopes, F., Santiago, A., Simões da Silva, L., Iqbal, N., Veljkovic, M. \& da Silva, J.G.S. 2015. Subframes with reverse channel connections to CFT composite columns - experimental evaluation. Advanced Steel Construction, 11(1): 110-125.

Oktavianus, Y., Goldsworthy, H. \& Gad, E. 2018. A blind bolted moment connection with an RBRF for composite moment resisting frames. $13^{\text {th }}$ International Conference on Steel, Space and Composite Structures 31 January - 2 February 2018, Perth, Australia.

SCI/BCSA. 2005. Joints in steel construction: simple connections. The Steel Construction Institute (SCI) \& The British Constructional Steelwork Association (BCSA).

Simões da Silva, L., Neves, L.C. \& Gomes, F.T. 2003. Rotational stiffness of RHS joints. Journal of Structural Engineering 129(4): 487-494.

Simões da Silva, L., Silva, L.C., Tankova, T., Craveiro, H., Simões, R., Costa, R., D’Aniello, M., Landolfo, R. 2021a. Performance of modular hybrid cold-formed/tubular structural system. Structures 30: 1006-1019.

Simões da Silva, L., Craveiro, H., Costa, R., Gervásio, H., Simões, R., Tankova, T., Iglesias, G., Agorostiza, A., Bureau, A., Nguyen, T.M., Veljkovic, M., Yan, R., Frade, H., Faria, R., Marques, B., Landolfo, R., D'Aniello, M., Poursadrullah, A. 2021b. INNO3DJOINTS - INNOvative 3D JOINTS for robust and economic hybrid tubular construction. Research Fund for Coal and Steel: Final Report, EU, Brussels.

Tizani, W. \& Ridley-Ellis, D.J. 2003. The performance of a new blind-bolt for moment-resisting connections. In: Jaurietta, M.A., Alonso, A., Chica, J.A. (eds.), Tubular Structures X, Proceedings of the $10^{\text {th }}$ international symposium on tubular structures, Madrid, Spain, 18-20 September 2003. Rotterdam: Balkema, 395-400.

Tizani, W., Al-Mughairi, A., Owen, J.S. \& Pitrakkos, T. 2013. Rotational stiffness of a blind-bolted connection to concrete-filled tubes using modified Hollo-bolt. Journal of Constructional Steel Research 80: 317-331.

Togo, T. 1967. Experimental study on mechanical behaviour of tubular joints, Doctoral Thesis, Osaka University (in Japanese).

Van-Long, H., Jaspart, J-P. \& Demonceau, J-F. 2015. Extended end-plate to concrete-filled rectangular column joint using long bolts. Journal of Constructional Steel Research 113: 156-168.

Wang, J. \& Zhang N. 2017. Performance of circular CFST column to steel beam joints with blind bolts. Journal of Constructional Steel Research 130: 36-52.

Wang, J-F., Han, L-H. \& Uy, B. 2009. Behaviour of flush end plate joints to concrete-filled steel tubular columns. Journal of Constructional Steel Research 65: 925-939. 
Wang, Z-Y. \& Wang Q-Y. 2016. Yield and ultimate strengths determination of a blind bolted endplate connection to square hollow section column. Engineering Structures 111: 345-369.

Wardenier, J., van der Vegte, G.J. \& Liu, D.K. 2007. Chord stress function for rectangular hollow section $\mathrm{X}$ and $\mathrm{T}$ joints In: Proceedings of the $17^{\text {th }}$ International Offshore and Polar Engineering Conference, Lisboa, Portugal, 2007. 3363-3370.

Wardenier J., Packer J.A., Zhao X.-L., Ven der Vegte A. 2010. Hollow section in structural applications. CIDECT, $2^{\text {nd }}$ edition.

Weynand K., Jaspart J.-P., Demonceau J.-F., Zhang L. 2015. Component method for tubular joints. CIDECT Report $16 \mathrm{~F}-3 / 15$.

Yeomans, N.F. 1998. Rectangular hollow section column connections using the Lindapter HolloBolt. In: Choo, Y.S., van der Vegte, G.J. (eds.), Tubular Structures VIII, Proceedings of the $8^{\text {th }}$ international symposium on tubular structures, Singapore, 1998. Rotterdam: Balkema, 559-566.

Zhou, G., An Y., Li, D. \& Ou J. 2019. Analytical model of moment-rotation relation for steel beam to CFST column T connections with bidirectional bolts. Engineering Structures 196: 109374. 